\title{
PERMUTATION: A Corpus-Based Approach for Modeling Personality and Multimodal Expression of Affects in Virtual Characters
}

\author{
Céline Clavel and Jean-Claude Martin \\ LIMSI-CNRS, BP 133, 91403 Orsay cedex, France \\ \{celine.clavel, martin\}@limsi.fr
}

\begin{abstract}
In order to improve the consistency of their affective multimodal behaviors, interactive virtual agents might benefit from a model of personality inspired from psychology. In this paper, we revisit the different approaches considered in personality psychology. We show that previous efforts to endow virtual agents with personality made only a limited use of these approaches. Finally, we introduce our PERMUTATION corpus-based framework.
\end{abstract}

Keywords: virtual agents, multimodality, emotion, personality.

\section{Introduction}

An interactive virtual agent is a human-computer interface in which an animated character displayed on the screen combines several human-like modalities such as speech, gesture and facial expressions. Using an interactive virtual agent is expected to lead to an intuitive and friendly interaction since it uses communication modalities that we all use every day. Researchers recently focused on how such virtual characters should express affective states across modalities and how that would be perceived by human subjects $[1,2,3,4]$.

In order to improve the consistency of their multimodal expressions of affects, interactive virtual agents might benefit from a model of personality inspired from psychology. This perspective raises several questions: how should affects and personality interact in the specification of the multimodal expression to be displayed by the virtual character? What are the relevant psychological models from which we can inspire from?

The first section of this paper surveys the different approaches to personality psychology to explain their interests and their limitations in terms of virtual agents. The second section shows that, although several attempts have been made to endow virtual characters with personality, current virtual characters are still limited when compared to the rich literature about human personality. The last section introduces a corpus-based framework to inform the expression of affective states in a virtual agent endowed with personality features. 


\section{Psychological Approaches to Personality}

One of the definitions of Personality [5] is "a set of organized, stable and individualized behaviors". The goal of personality research is to try to describe, to explain and to predict this set. Today an integrative approach of personality is recommended. Six levels of analysis are proposed to provide a global overview of human personality: the trait-dispositional level, the psychodynamic-motivational level, the phenomenological level, the behavioral-conditioning level, the social cognitive level and the biological level. Each level provides a specific contribution to the general understanding of personality and behavior. These levels have been partly addressed by several major historical approaches that we describe below.

\section{The Lexical Approach}

The lexical approach to personality proposes to classify the terms of natural language that are used to describe and understand human qualities. It is based on the postulate that the frequency of a word used to describe people corresponds to the importance accorded to such words in human interactions. Factorial analysis has been employed in order to reduce and organize the thousands of adjectives into a smaller number of dimensions. Factorial analysis is applied to process interpersonal differences of the dispositional tendencies reported during self-assessments. The lexical approach enables to define constructs that have a relative temporal stability, a good predictive value, that are applicable to different cultures and that are socially important. These constructs correspond to "personality traits". Rolland [6] defines traits as "coherent sets of cognitions, emotions and behaviors that demonstrate a temporal stability and cross situational consistency". Such traits result from inferences and not from a directly observable reality. Personality traits are defined as general, durable, relatively stable, characteristics, used to assess and explain the behavior. Different models and psychometric tools based on the lexical approach have been developed: the Eysenck Personality Inventory, 16PF, and NEOPI R.

Eysenck [7] described personality from the clinical descriptions of patients displaying psychopathological behaviors. He focused on Extraversion / Introversion and Neuroticism / Emotional stability. A third factor was present in his previous work: Psychotism. Each trait is bipolar. Eysenck developed a psychometric tool to assess personality: the Eysenck Personality Inventory (EPI). However Eysenck grants little importance to the impact of education in the development of personality and defends the idea that personality's factors are determined primarily by heredity.

Cattell [8] wanted to identify all personality traits that an individual might possess out of language. From 4500 words describing personality, he established a list of 171 words. He asked hundreds of subjects to assess whether they considered themselves to be well described by these words. He also asked other people to evaluate these same people. He identified 16 personality traits (16PF). However, some of these factors are strongly correlated and five factors of second order come out of these 16: Extraversion, Anxiety, Hardness / Intransigence, Independence, and Self-control.

The Big Five model (FFM) proposed by Costa and McCrae describes personality with two levels. The facets propose a fine and accurate description of personality. A domain corresponds to a group of facets. The big five model identifies 5 basic dimensions through factorial analysis. Each dimension includes specific 
characteristics of personality represented by adjectives on a bipolar scale and is composed of six facets which specify them. Neuroticism is defined as a system regulating avoidance behaviors $[9,10]$. Its role is to preserve the organism of pain by anticipating and by activating surveillance behaviors. A subject with a high neuroticism score presents a very critical vision of herself. She also has the tendency to feel frequently and intensively a wide range of negative emotions. Extraversion is characterized as a system of regulation of approach behaviors. A high score on this trait reveals a strong sensitivity to pleasant stimuli and a tendency to feel frequently and intensively positive emotions. Openness to Experience results in broad and varied interests, a capacity to search for and to live new and unusual experiences. It is a system of regulation of reactions to novelty. A person who presents a high score manifests particular attention to his own emotional universe. Agreeableness refers to interactions with others and especially to the tone of relationship with others. It corresponds to a system of regulation of the balance in relations and exchanges. A high score corresponds to altruist individuals who worry first about the well-being of others and who have tendency to trust others. Conscientiousness relates to motivation, organization and perseverance in the conducts oriented towards a goal. A high score corresponds to a person who tends to set long-term goals, to organize her action and accepts the constraints bound to the satisfaction differed of the needs and desires.

Studies revealed that there is a consensus among judges to characterize target individuals on certain traits (extraversion and conscientiousness). The characterizations of target individuals by judges tend to be convergent but also correspond to selfdescriptions of targets, even when the judges have minimum indications about target individuals [11].

Costa and McCrae elaborated the NEOPI R that is the most widely used personality's inventory. It includes 240 items, 48 by domain, 8 by facet. It was translated into several languages $[12,13]$. The scores on personality traits found among young adults (of more than 30 years) are relatively stable with the advancement in age. Costa \& McCrae [14] consider the traits as endogenous trends with a biological basis. According to Costa and McCrae, the model of Big Five represents the universal structure of individual differences.

The goal of the Big Five model is to provide descriptive models to classify individuals according to their abstract dispositional trends and not to explain their behaviors. The significance of adjectives used in natural language is complex and it is relevant to describe them by their polysemy [15]: they can describe the behaviors, the states and evaluate the social utility of others. Lexical models attach little importance to the role of the environment in the implementation processes of personality. Finally these models are interested solely in the interpersonal differences. These criticisms led to two other currents of research.

\section{The Psychosocial Approach}

This approach sees in the expression of traits the description of the behaviors, the states and the evaluation of the social utility of others. Rather than considering a trait as the expression of an individual trends, this approach suggests to consider the trait as an act depends on the sense given to the situation : to say how we behaves, but also to express our value in social relationships and express our internal states. Two approaches characterize this current of research: 1) an approach centered on the value 
of adjectives, and 2) an approach centered on the significance of the adjectives. Only the first approach will be presented here because it is more relevant for virtual characters since it enables to determine the representations which the subjects develop concerning the agents.

According to this approach, the perception of individual differences is an evaluation of others and not a description of their supposed properties $[16,17][18]$. People do not judge others in order to describe them as accurately as possible, but instead in order to prepare an adequate interaction with them according to the utility that they represent. So people would develop a personality's implicit theory (TIP). Two dimensions of the values of adjective structure personality traits. The first dimension concerns approach vs. avoidance. We consider as positive everything that relates to approach and negative what relates to avoidance. The second dimension characterizes the skills, the power and the social status of people. Thus, adjectives convey information on people about their emotional $\left(1^{\text {st }}\right.$ dimension $)$ or social value ( $2^{\text {nd }}$ dimension).

Wiggins' [19] proposes a circumplex model reporting the structure of interpersonal adjectives. Beauvois [20, 21] proposed social analysis that considers the value of a person as depending on her interpersonal relations or social relationships. Social desirability corresponds to the knowledge that people have about what is considered to be desirable in a society. Social utility refers to the knowledge that people have about the likelihood of success of a person in the social life according to her level of adhesion to the surrounding social organization.

\section{The Socio-Cognitive Approach}

Bandura [22, 23] aims to explain human conducts through the understanding of underlying mechanisms of individual actions. This approach attaches importance to the social context and the intra individual differences. It focuses primarily on how the individual selects, estimates, and processes information about others and about the world. It is about understanding the cognitive, emotional, and social processes that characterizes individuals. Three entries contribute to the development of this approach according to Cervone [24]: 1) a meta-theoretical framework that can organize research on the individual, 2) theories which study variables characterizing the architecture of personality and which enable predictions and evaluations at the individual level, and 3) theories focused on the demonstration of the dynamics and socio-cognitive processes that underlie a given phenomenon. CAPS (CognitiveAffective Personality Systems) is a cognitive and emotional model of personality [25]. It considers the beliefs and goals of individuals. Personality does not result from the sum of isolated and independent individual characteristics. It is therefore important to study the organization of these variables. This model considers that the person and the environmental situation are continually in interaction and influence mutually. It questions the lexical approach theories based on average behavioral tendencies. The CAPS model considers the variability in behaviors observed in different situations as being informative about the individual. However CAPS remains a conceptual framework and does not specify which variables are necessary to consider for modeling the structure of personality. The KAPA model (Knowledge and Appraisal Personality Architecture) attempts to answer this question. 
The KAPA model by Cervone [26] distinguishes three types of mental contents depending on the direction of intentionality. Beliefs are directed from the mind towards the world. Goals are directed from the world towards the mind. A mental content is not true or false but reflects an intention to reach a future state. It serves as a criterion for assessing the quality of an entity. This is referred to as Evaluative standard. These types of mental content are involved in knowledge and appraisal:"Knowledge is an enduring structural feature of personality. Appraisals are dynamic personality processes. People possess vast repertoires of knowledge, but only a small subset is active at a time, and is thus potentially influential to appraisal processes".

\section{Virtual Agents with a Personality}

\section{Psychosocial Approach to Human-Computer Interaction}

Several studies considered how users build representation of their computers. Users apply to their computer some stereotypes of daily life. Gender stereotypes were observed: users trust more a machine endowed with a male voice and estimate that a machine having a female voice has higher relational skills [27]. Nass et al. [28] observed that standards of social utility and social desirability also applied to HCI. The performances of computers are judged as being superior when they are valorized by other computers that when it is the computer that welcomes itself. A computer which congratulates itself or which criticizes other computers is perceived as being less friendly than a computer which admires the others and which displays self criticism. Otherwise computers that criticize are perceived as being smarter than computers that praise. Other researchers studied the impact of users' personality on their representation of their computer. Nass et al. [29] propose a circumplex model of inter-personal behavior based on two "factors": Extraversion (dominant vs. submissive) and Agreeableness (cordial vs. hostile). They observed that subjects preferred a computer which looked like them. The same result is obtained for the skill.

\section{Models Based on the Lexical Approach}

Most models of virtual agents with personality inspire from the lexical approach, and the Big Five model [30, 31, 32, 33, 34]. According to André et al. [35], the model developed by Costa \& McCrae presents the advantage to be descriptive and is considered like a support of the emotional dimension. Some architecture focuses on a few traits (extraversion, agreeableness and neuroticism for André, Klesen, Gebhard, Allen \& Rist, or the neuroticism for Hermann, Melcher, Rank \& Trappl). Ball and Breese [36] use the dominance and friendliness dimensions which they consider as being more relevant within the framework of interpersonal relations.

\section{Models based on the personality's socio-cognitive approach}

Models of virtual agents based on the socio-cognitive approach to personality are few. Moffat [37] developed a model to create personalities of virtual agents using the works of Mischel. In the same way, Sandercock et al. [38] worked on the development of believable agents for interactive applications. These authors focused 
on the intra-individual variability of agents. Their goal is to produce agents whose conducts depend on the situation but remain coherent. These authors note that most implementations of personality are static and based on the theory of traits. However according to Sandercock et al. [38], the lexical approach doesn't propose any help concerning the modulation of the expression of personality's traits depending on the situation.

\begin{tabular}{|c|c|c|c|}
\hline & $\begin{array}{c}\text { Lexical } \\
\text { approach }\end{array}$ & $\begin{array}{l}\text { Psychosocial } \\
\text { approach }\end{array}$ & Sociocognitive approach \\
\hline  & $\begin{array}{l}\text { - Descriptive model to } \\
\text { classify individuals } \\
\text { according to their } \\
\text { abstract dispositional } \\
\text { trends } \\
\text { - Traits as endogenous } \\
\text { trends with a } \\
\text { biological basis } \\
\text { - Factorial Analyses } \\
\text { - Psychometric tools: } \\
\text { EPI, 16PF, Big Five } \\
\text { - Interpersonal } \\
\text { differences }\end{array}$ & $\begin{array}{l}\text { - Perception of } \\
\text { individual differences } \\
\text { is mostly an evaluation } \\
\text { of others } \\
\text { - Influence of social } \\
\text { interactions } \\
\text { - Role of Social } \\
\text { desirability } \\
\text { - Role of Social utility }\end{array}$ & $\begin{array}{l}\text { - Explanatory model of } \\
\text { human behavior via the } \\
\text { understanding of the } \\
\text { underlying mechanisms } \\
\text { of individual actions } \\
\text { - Influence of social } \\
\text { context } \\
\text { - Integration of the } \\
\text { different individual } \\
\text { variables } \\
\text { - Intra-individual } \\
\text { variability } \\
\text { - CAPS KAPA }\end{array}$ \\
\hline 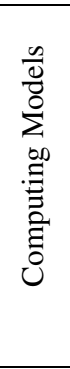 & $\begin{array}{l}\text { - Gebhard, ALMA } \\
\text { - Egges et al. A Model } \\
\text { for Personality and } \\
\text { Emotion Simulation } \\
\text { - Breese \& Ball models } \\
\text { of emotions and } \\
\text { personality encoded as } \\
\text { Bayesian networks } \\
\text { - André et al. Persona } \\
\text { System } \\
\end{array}$ & $\begin{array}{l}\text { - Nass et al. CASA } \\
\text { "Computers Are Social } \\
\text { Actors" }\end{array}$ & $\begin{array}{l}\text { - Moffat } \\
\text { - Sandercock et al. }\end{array}$ \\
\hline \multicolumn{4}{|c|}{$\begin{array}{l}\text { Computing Models combining different app } \\
\text { - Read et al. The Personality-enabled Architecture for Cognition } \\
\text { - Poznanski \& Thagards : the SPOT model }\end{array}$} \\
\hline
\end{tabular}

\section{Models combining different approaches of the personality}

Most computer models trying to introduce the concept of personality in virtual characters combine different perspectives [34, 39, 40, 41]. For example, Poznanski \& Thagards [42] developed the SPOT model (Simulating Personality Over Time) based on the lexical approach and the socio-cognitive. It is composed of four components: personality, emotion, input describing the situation, and output describing the behaviors. The personality component is based on the Big Five model. Each of the traits has its behavioral pattern. Personality's nodes in SPOT are connected with the behavioral output based on behavioral trends for a given trait. The extrovert node is strongly connected to behaviors that characterize extrovert humans. It is also loosely connected to behaviors that are not extrovert. These various connection strengths represent the genetic predispositions of a person for the traits. This model also relies on theories of social learning about personality. Each "situation" input is connected 
with various strengths to a corresponding "behavior" output as well as to other behaviors. The connections between nodes and their strength are determined from the emotional and behavioral tendencies known to the Big Five.

\section{The PERMUTATION Corpus-Based Approach}

Existing personality models used in virtual agents are mainly based on the lexical approach to personality. They are inspired by the socio-cognitive approach only when the situation is considered important in the development of personality. Few virtual agent studies considered the cognitive dimension of personality and tried to develop profiles of cognitive functioning for virtual agents.

Among socio-cognitive approaches to personality psychology, cognitive styles describe one's cognitive functioning but also certain aspects of one's social behaviors [43]. They relate to characteristic ways to perceive, remember, think and solve problems [44, 45]. Thus, they describe the style of mental activity rather than its content. They are deduced from our stable individual differences in the way of organizing and of dealing with information. One of the most studied cognitive styles in psychology is the field-dependency dimension (FID). This cognitive style relates to the usual and favorite way of perceiving the information. People that are independent from the field (FI) have an analytical vision; they transform the information at their disposal to organize it according to their own criteria. Their conducts are rather directed toward objects and they tend to take the lead in social interactions. In contrast, people that are depending on the field (FD) are more sensitive to the perceptive and conceptual organization of the information. They are very attentive to interpersonal relations and tend to ask for information from others. Research on expressive agent did not invest much this dimension of personality. Few researches tried to assign the properties which characterize certain cognitive functioning to animated characters. However such properties of mental activity might participate in the multimodal expression of emotion since one goal of multimodal expressions of emotion is to inform others of the way we evaluate the current situation. Our hypothesis is that cognitive style can be perceived in the multimodal expression of emotions. For example "FI" people do not consider much the point of view of others and tend to dictate their opinion. They might not try to control their anger and might adopt broader and quicker movements than "FD" people.

To determine the multimodal emotional expression associated to every pole of the cognitive style (FID), we have developed the PERMUTATION corpus-based approach (PERsonality MUltimodal InTerAcTION). TV series provide recurrent behaviors displayed by a variety of characters over time when faced with different emotional situations. They might provide more spontaneous data than acted protocols using in-lab conditions. They enable to consider the role of the situation in the emergence of the emotional process and are informative on the stability of the emotional expression in the course of time according to the personality of the characters.

We designed a questionnaire for assessing the various parameters of the DIC (orientation of the behaviors, type of interaction and type of perception). 50 subjects had to estimate the cognitive style of seven television series characters with the help of this questionnaire. This allowed us to select five female characters recognized by the subjects either as being either strongly FI or strongly FD. 
Video samples featuring emotional behaviors of these characters were then collected. Five emotion families were considered (happiness, anger, surprise, fear and sadness). 100 sequences have been selected, for a total duration of 2568 seconds. These video samples were then annotated by other subjects with respect to the multimodal emotional expression they perceive.

Preliminary results reveal that subjects estimate the emotional events differently according to their emotional tone. They judge that the positive episodes are more pleasant and more favorable to the success of the character's goals than the negative situations. Besides, when we compare the evaluation realized by subjects for two characters who are perceived as having the same cognitive style, no difference appears. The subjects consider that characters having the same cognitive style and facing similar situations, realize the same type of emotional assessment of the situation. Movement quality was observed to be a discriminative features of some acted emotions [46]. In our data, the subjects judged that the temporal amplitude, the intensity and the general level of activation vary according to the nature of the expressed emotion. When a character expresses Anger, her gestures are perceived to be faster, more intense and the general level of activation is higher than when the character expresses Joy. Furthermore, as seen previously, two characters having the same cognitive style and expressing the same type of emotion do not present differences as for the quality of their movements.

\section{Conclusion and Future Directions}

We surveyed the different models of personality in virtual agents and the underlying approaches in Psychology. We introduced the PERMUTATION corpus-based approach which aims at informing the design of virtual agents that are able to reflect their cognitive style in their multimodal expression of emotion. Such data can be useful for the definition a library of multimodal behaviors associated to different emotions according to cognitive styles. Future directions include validating the model by conducting similar perceptive studies with users interacting PERMUTATIONbased animated characters.

Acknowledgments. The research presented here was partly supported by the project "ANR TLOG Affective Avatars". The authors thank the students who participated in the study.

\section{Bibliography}

1. Martin, J.-C., Niewiadomski, R., Devillers, L., Buisine, S., Pelachaud, C.: Multimodal Complex Emotions: Gesture Expressivity And Blended Facial Expressions. Special issue of the Journal of Humanoid Robotics on Achieving Human-like Qualities in Interactive Virtual and Physical Humanoids 3, 3 (2006) (Pelachaud, C., Canamero, L. (eds.))

2. Buisine, S., Abrilian, S., Niewiadomski, R., Martin, J.-C., Devillers, L., Pelachaud, C.: Perception of Blended Emotions: from Video Corpus to Expressive Agent. In: Gratch, J., Young, M., Aylett, R.S., Ballin, D., Olivier, P. (eds.) IVA 2006. LNCS, vol. 4133, pp. 93 106. Springer, Heidelberg (2006) 
3. Pelachaud, C.: Multimodal expressive embodied conversational agent. ACM Multimedia, Brave New Topics session, Singapore, 683-689 (2005)

4. Gratch, J., Marsella, S.: Lessons for Emotion Psychology for the Design of Lifelike Characters. In: Journal of Applied Artificial Intelligence (special issue on Educational Agents - Beyond Virtual Tutors), vol. 19, pp. 3-4 (2005)

5. Mischel, W., Shoda, Y., Smith, R.E.: Introduction to Personality: Toward an Integration, 7th edn. J. Wiley \& Sons, Hoboken (2004)

6. Rolland, J.P.: L'évaluation de la personnalité. Mardaga, Sprimont (2004)

7. Eysenck, H.J.: The structure of human personality, London, Methuen (1970)

8. Cattell, R.B.: Personality and mood by questionnaire, San Francisco, Jossey-Bass (1973)

9. Davidson, R.: Affective style and affective disorders: Perspective from neurosciences. Cognition and Emotion 12, 3 (1998)

10. Gray, J.: The neurobiology of temperament. In: Exploration in temperament: International perspectives on theory and measurement. Plenum Press, New York (1991)

11. Borkenau, P., Liebler, A.: Trait inferences: sources of validity at zero acquaintance. Journal of Personality and Social Psychology 62 (1992)

12. Mlaĉiĉ, B., Ostendorf, F.: Taxonomy and structure of Croatian personality-descriptive adjectives. European Journal of Personality 19 (2005)

13. Saucier, G., Goldberg, L.: Personnalité, caractère et tempérament: La structure translinguistique des traits. Psychologie Française 51 (2006)

14. McCrae, R.R., Costa Jr., P.T.: A Five-Factor Theory of personality. Handbook of personality psychology. Guilford, New York (1999)

15. Mignon, A., Mollaret, P.: Quel type d'approche scientifique pour la description de la personnalité? Psychologie Française 51 (2006)

16. Beauvois, J., Dubois, N.: Traits as evaluative categories. Cahiers de Psychologie Cognitive/Current Psychology of Cognition 12 (1992)

17. Beauvois, J., Dubois, N.: Affordances in social judgment: Experimental proof of why it is a mistake to ignore how others behave towards a target and look solely at how the target behaves. Swiss Journal of Psychology/Schweizerische Zeitschrift für Psychologie/Revue Suisse de Psychologie 59 (2000)

18. Mignon, A., Mollaret, P.: Applying the affordance conception of traits: a person perception study. Personality and Social Psychology Bulletin 28 (2002)

19. Wiggins, J.S.: A Psychological taxonomy of trait-descriptive terms: the interpersonal domain. Journal of Personality and Social Psychology 37 (1979)

20. Beauvois, J.L.: La connaissance des utilités sociales. Psychologie française 40 (1995)

21. Beauvois, J.L.: Judgment norms, social utility, and indvidualism. A sociocognitive approach to social norms. Routledge, London (2003)

22. Bandura, A.: Self-efficacy: Toward a unifying theory of behavioral change. Psychological Review 84 (1977)

23. Bandura, A.: Social cognitive theory: An agentic perspective. Annual review of psychology 52 (2001)

24. Cervone, D.: Personality Architecture: Within-Person Structures and Processes. Annual Review of Psychology 56, 1 (2005)

25. Mischel, W., Shoda, Y.: A cognitive-affective system theory of personality: Reconceptualizing situations, dispositions, dynamics, and invariance in personality structure. Psychological Review 102 (1995)

26. Cervone, D.: Personality assessment: tapping the social-cognitive architecture of personality. Behavior Therapy 35 (2004) 
27. Nass, C., Moon, Y., Green, N.: Are Machines Gender Neutral? Gender-Stereotypic Responses to Computers With Voices. Journal of Applied Social Psychology 27 (1997)

28. Nass, C., Steuer, J., Henriksen, L., Dryer, D.: Machines, social attributions, and ethopoeia: Performance assessments of computers subsequent to 'self-' or 'other-' evaluations. International Journal of Human-Computer Studies 40 (1994)

29. Nass, C., Moon, Y., Fogg, B.J., Reeves, B., Dryer, D.: Can computer personalities be human personalities. International Journal Human Computer Studies 43 (1995)

30. Egges, A., Kshirsagar, S., Magnenat-Thalmann, N.: A Model for Personality and Emotion Simulation. Knowledge Based Intelligent information and engineering systems (2003)

31. Kshirsagar, S.: A multilayer personality model. In: 2nd international symposium on Smart graphics SMARTGRAPH 2002 Hawthorne, New York, pp. 107-115 (2002)

32. Hermann, C., Melcher, H., Rank, S., Trappl, R.: Neuroticism - A Competitive Advantage. In: Pelachaud, C., Martin, J.-C., André, E., Chollet, G., Karpouzis, K., Pelé, D. (eds.) IVA 2007. LNCS, vol. 4722, pp. 64-71. Springer, Heidelberg (2007)

33. Delgado-Mata, C., Ibáñez, J.: Behavioural Reactive Agents for Video Game Opponents with Personalities. In: Pelachaud, C., Martin, J.-C., André, E., Chollet, G., Karpouzis, K., Pelé, D. (eds.) IVA 2007. LNCS, vol. 4722, pp. 371-372. Springer, Heidelberg (2007)

34. Gebhard, P.: ALMA - A Layered Model of Affect. In: Fourth International Joint Conference on Autonomous Agents and Multiagent Systems (AAMAS 2005) Utrecht, pp. 29-36 (2005)

35. André, E., Klesen, M., Gebhard, P., Allen, S., Rist, T.: Integrating Models of Personality and Emotions into Lifelike Characters workshop on Affect in Interactions - Towards a new Generation of Interfaces in conjunction with the 3rd i3 Annual Conference, Siena, Italy, pp. 136-149 (1999)

36. Breese, J., Ball, G.: Modeling emotional state and personality for conversational agents, pp. 7-13. AAAI, Menlo Park (1998)

37. Moffat, D.: Personality Parameters and Programs. Berlin

38. Sandercock, J., Padgham, L., Zambetta, F.: Creating Adaptive and Individual Personalities. In: Gratch, J., Young, M., Aylett, R.S., Ballin, D., Olivier, P. (eds.) IVA 2006. LNCS, vol. 4133, pp. 357-368. Springer, Heidelberg (2006)

39. Read, S.J., Miller, L.: Virtual Personalities: A Neural Network Model of Personality. Personality and Social Psychology Review 6 (2002)

40. Ghasem-Aghaee, N., Ören, T.I.: Cognitive Complexity and Dynamic Personality in Agent Simulation. Computers in Human Behavior 23 (2007)

41. Read, S., Miller, L., Kostygina, A., Chopra, G., Christensen, J.L., Corsbie-Massay, C., Zachary, W., Lementec, J., Iordanov, V., Rosoff, A.: The Personality-Enabled Architecture for Cognition (PAC). In: Paiva, A.C.R., Prada, R., Picard, R.W. (eds.) ACII 2007. LNCS, vol. 4738, pp. 735-736. Springer, Heidelberg (2007)

42. Poznanski, M., Thagard, P.: Changing personalities: towards realistic virtual characters. Journal of Experimental \& Theoretical Artificial Intelligence 17 (2005)

43. Huteau, M.: Les conceptions cognitives de la personnalité. PUF Paris (1985)

44. Witkin, H.: A cognitive-style perspective on evaluation and guidance. In Proceedings of the Invitational Conference on Testing Problems (1973)

45. Messick, S.: The matter of style: manifestations of personality in cognition, learning, and teaching. Educational Psychologist 29, 3 (1994)

46. Wallbott, H.G.: Bodily expression of emotion. European Journal of Social Psychology 28 (1998) 